\title{
Temporal Variations in the Abundance and Diversity of Surface Zooplankton in the South Coast of Sri Lanka
}

\author{
Wimalasiri H.B.U.G.M. ${ }^{1 *}$, Jinadasa S.U.P. ${ }^{2}$ and Dissanayake D.C.T. ${ }^{1}$ \\ ${ }^{1}$ Department of Zoology, University of Sri Jayewardenepura, Sri Lanka \\ ${ }^{2}$ National Aquatic resources Research and Development Agency, Sri Lanka \\ *udshikamanike@gmial.com
}

\begin{abstract}
Zooplankton have extensively studied in the Indian Ocean, but very few systematic studies have been carried out in the marine waters around Sri Lanka. This study aimed to understand the temporal variations in the abundance and diversity of surface zooplankton in the south coast of Sri Lanka. Surface zooplankton samples were collected at five different locations in the south coast of Sri Lanka in November 2015 (second inter monsoon), December 2015 (Northeast monsoon, NE) and May 2016 (Southwest monsoon SW) using R/V Samuddrika. The vertical hauls of zooplankton were collected from $5 \mathrm{~m}$ depth at each station using WP-2 net with $180 \mu \mathrm{m}$ mesh size and samples were immediately preserved in $5 \%$ buffered formalin. At the laboratory, zooplankton were identified to the lowest possible taxon using existing guides, species diversity, abundance $\left(\mathrm{ind} / \mathrm{m}^{3}\right.$ ), evenness and richness were estimated with respect to three different sampling phases. The data were subjected to hierarchical cluster analysis to identify the similarity between temporal variation and zooplankton abundance. A total of 152 zooplankton species were identified during this study. Species belonging to phylum Arthropoda appeared be the most abundant group and their standing crop (whole time period and sites) was $1906 \pm 115 \mathrm{ind} / \mathrm{m}^{3}$. Arthropods occupied nearly $86 \%$ of total zooplankton community. Among arthropods, order Poecilostomatoida showed the highest abundance $\left(858 \pm 8 \mathrm{ind} / \mathrm{m}^{3}\right)$ followed by phylum Protochordata $\left(\sim 3 \%\right.$ and average of $\left.74 \mathrm{ind} / \mathrm{m}^{3}\right)$ chetognaths $(2.1 \%)$ and mollusks $(\sim 1.9 \%)$. The highest species abundance was recorded in Novemver $\left(1392 \pm 5 \mathrm{ind} / \mathrm{m}^{3}\right)$ and lowest was in May $\left(360 \pm 2 \mathrm{ind} / \mathrm{m}^{3}\right)$. Species diversity was also highest in November and lowest in May. Cluster analysis revealed two clearly visible abundance clusters with respect to time. The results indicated that there are significant temporal variations in zooplankton abundance (ANOVA, $\mathrm{P}<0.05$ ) in the South coast of Sri Lanka.
\end{abstract}

Keywords: Zooplankton, Abundance, Diversity, Cluster analysis

Proceedings of the International Forestry and Environment Symposium 2016, Department of Forestry and Environmental Science, University of Sri Jayewardenepura, Sri Lanka. 